Matthew Watkins

\title{
An Audio-visual Approach to Teaching the Social Aspects of Sustainable Product Design
}

\begin{abstract}
This paper considers the impact of audio-visual resources in enabling students to develop an understanding of the social aspects of sustainable product design. Building on literature concerning the learning preferences of 'Net Generation' learners, three audio-visual workshops were developed to introduce students to the wider social aspects of sustainability and encourage students to reflect upon the impact of their practice. The workshops were delivered in five universities in Britain and Ireland among undergraduate and postgraduate students. They were designed to encourage students to reflect upon carefully designed audio-visual materials in a group-based environment, seeking to foster the preferences of Net Generation learners through collaborative learning and learning through discovery. It also sought to address the perceived weaknesses of this generation of learners by encouraging critical reflection. The workshops proved to be popular with students and were successful in enabling them to grasp the complexity of the social aspects of sustainable design in a short span of time, as well as in encouraging personal responses and creative problem solving through an exploration of design thinking solutions.
\end{abstract}

Keywords: Audio-visual resources, design education, product design, social sustainability

\section{Introduction}

Sustainability as described by the triple bottom line (Elkington, 1998) considers three pillars: economic, environmental and social concerns - considering all three aspects to be of equal value. While sustainable design education has emphasised and made inroads into addressing the environmental considerations and impact related to products and services, it has neglected the social considerations, particularly social wellbeing (Griffiths \& O'Rafferty, 2010). A review of literature uncovered a distinct lack of sources addressing social equity within sustainable product design, corresponding with findings by Vezzoli (2006) who calls the socialethical dimension of sustainable design a new research frontier, describing the field as relatively unexplored, with a lack of teaching proposals.

Prior to the undertaking of the research outlined in this paper, a set of criteria were defined and developed to guide the content of the 'Rethinking Design' workshops in respect to the social dimension of Sustainable Product Design (SPD) (Watkins, 2013). In addition, prior research conducted within the doctoral study (Watkins, 2014a) also sought input from leading academics in SPD within the UK and these findings informed the direction of the research presented in this paper.

This research conducted among academics concerned the difficulties that they encounter in teaching the social dimension of sustainable design and findings from these academic interviews suggest that students and lecturers often find it easier to address the more tangible environmental concerns than the complex often intangible social issues (Watkins, 2014a).

Academics noted that addressing the social aspects of SPD requires a transformative holistic approach rather than the traditional transmission approach with measurable outcomes (Watkins, 2014a). Academics also noted that the social aspects of SPD are more suited to teaching or discussion in small groups within the context of a student's work in a studio or tutorial setting (Watkins, 2014a). This suggests that larger groups of students inhibit the ability to engage in discussion, with academics describing a tendency to revert to teaching solely the environmental aspects when larger groups were involved. These findings echo those de- 
scribed by Ramirez (2007b) in his worldwide survey of sustainability in industrial design education, which found that while the teaching of environmental considerations of sustainable design is widespread, the additional social and ethical considerations are often neglected (Ramirez, 2007b).

These earlier findings were considered within the design and development of the 'Rethinking Design' workshops. The impact of these workshops is explored and evaluated through two separate publications. This paper presents the impact of the audio-visual approach using popular music and carefully selected photography to convey meaning and the breadth of social sustainability, while a previously published paper considers how deep learning was fostered in the workshops through reflection, relevance and group interaction (Watkins, 2014b).

One of the key considerations of the research outlined is this paper is to ensure that the format of learning resources is relevant to the students and takes account of their learning styles, to facilitate their learning in a manner that is accessible and effective. Therefore, the following two sections consider the students' preferences and modes for delivering the content.

\section{Contemporary learners}

There is a wealth of literature that specifically discusses the nature of the current cohort of students in higher education and the impact this has on higher education. The current generation of students are referred to in a number of ways with multiple terms being used within the literature including: 'Net-Generation' (Oblinger \& Oblinger, 2005a; Tapscott, 1998), 'Millennials' (Holliday \& Li, 2004; Howe \& Strauss, 2003) and 'Digital Natives' (Palfrey \& Gasser, 2008; Prensky, 2001). This generation of students are typically defined as individuals born from 1982 onwards (Howe \& Strauss, 2003; Oblinger \& Oblinger, 2005a). However, the differentiating factor for the 'Net Generation' may be their technological experience rather than just their age, as this generation of students would have all been typically using computers by time they were 16 to 18 years old (Oblinger \& Oblinger, 2005b). The research presented in this paper commenced in 2010 at which point the oldest 'Net-Generation' learners would have been 28 years old; therefore, it is entirely appropriate that the research considers the needs of this generation considering that typical undergraduates would have been aged between 18 and 22 years. Therefore, the range of learners that could be considered 'Net Generation' learners could encompass the majority of the students involved in undergraduate and postgraduate study in the UK at the time (Watkins, 2014b).

The literature states that Net Generation learners learn in different ways and have differing learning preferences to the preceding generation (Barnes, Marateo, \& Ferris, 2007). It is suggested that these differences are related to the pervasiveness of technology and digital media, with the emergence of the internet and social media as well as wider changes in the social climate (Tapscott, 2009) that they have grown up in. A fuller explanation of the 'Net Generation' is given in an earlier paper (Watkins, 2014b).

\section{Learning preferences}

A summary of the key considerations are summarised below, with a fuller explanation given in an earlier paper (Watkins, 2014b). 'Net Generation' learners in Higher Education prefer an autonomous style of learning with preferences for experiential learning (Barnes, Marateo \& Ferris, 2007) and learning by doing (McNeely, 2005). Therefore students prefer a greater emphasis on exploratory learning by discovery, as individuals or in collaboration with their peers, to the more traditional lecture format where information is given to them (Oblinger \& Oblinger, 2005b; Tapscott, 2009). Literature recognises that this exploratory style enhances 
the way in which students retain information and are able to use it in more creative and meaningful ways (Tapscott, 1998).

Net Generation learners are socially orientated and are attracted to activities that foster social interaction through interactive learning (Barnes, Marateo \& Ferris, 2007; Tapscott, 2009), peer to peer learning (Oblinger \& Oblinger, 2005b) and group work (Howe \& Strauss, 2003; Oblinger \& Oblinger, 2005a; Barnes, Marateo \& Ferris, 2007; Tapscott, 2009). An interesting consequence of this social nature is that the Net Generation typically dislikes online or distance learning environments (McNeely, 2005), despite the technological focus of such an approach, preferring instead the social interaction of a traditional learning environment. Tapscott (2009) describes how students can begin to internalise their learning through discussion in a group environment. Oblinger \& Oblinger (2005b) further describe how a peerto-peer approach is often seen more credible than a teacher-led approach among Net Generation learners.

Net Generation learners are visual learners who retain, on average, $30 \%$ of what they see but only $10 \%$ of what they read (Oblinger \& Oblinger, 2005b); therefore, such students are more comfortable with image-rich environments than with text (Oblinger \& Oblinger, 2005b; Tapscott, 2009; Windham, 2005). Net Generation learners have an enhanced visual literacy with the ability to read images and an innate ability to communicate through visual methods, combining images, text and sound seamlessly (Oblinger \& Oblinger, 2005b). Their abilities have been widely demonstrated by the prevalence of amateur You Tube content.

Net Generation learners are also characterised by their ability to multitask (Barnes, Marateo \& Ferris, 2007; Holliday \& Li, 2004; Prensky, 2001), quickly shifting their attention from one task to another and are able work on multiple tasks simultaneously (Oblinger \& Oblinger, 2005b). This also presents an ability to handle and process information in nonlinear ways (Oblinger \& Oblinger, 2005b) and more quickly when compared to previous generations. However, crucially for educators this means that Net Generation learners expect rapid responses (Oblinger \& Oblinger, 2005b). This ability to multitask and adopt a rapid pace, however, is cited as detrimental to the student's ability to reflect and adopt critical thinking skills and therefore could be considered a weakness of the Net Generation (Holliday \& $\mathrm{Li}$, 2004; Oblinger \& Oblinger, 2005b; Prensky, 2001).

\section{Audio-visual learning resources}

Audio-visual learning resources are referred to in many different ways across disciplines. However, for the purposes of this paper the author is only concerned with the use of audiovisual resources in the physical classroom context, rather than a distance learning IT-based environment, as this doesn't suit the preferences of the 'Net Generation'. The use of audiovisual methods can take the form of either an alternative to, or an additional component to traditional classroom-based teaching and learning approaches. Therefore, throughout the study when the term 'audio-visual' is used it refers to the use of audio-visual content within a physical classroom environment that is delivered face to face with students, with the intention of enhancing teaching and learning.

Audio-visual learning approaches are being explored for numerous reasons including the recognition of a student preference for a visual format in the 'Net Generation' literature and the growing prevalence of an audio-visual culture through formats such as YouTube. Audio-visual learning approaches are also noted in Sustainable Design literature in respect to the teaching of ethics and responsible practice to engineering (Perdan, Azapagic \& Clift, 2000) and design students (Griffith \& Bamford, 2007). Griffith \& Bamford (2007) cite the use of introductory audio-visual presentations as a means of promoting interest in responsible design among students, and supporting lecture content and stimulating discussion and activities in tutorials. However, very little detail is given on the development of choice for or 
intent behind such audio-visual resources within these papers. Furthermore, there is a lack of literature in the design field discussing the use and benefits of an audio-visual teaching approach.

Therefore, this paper considers support for the use of audio-visual teaching methods from the field of sociology education, where the practice of using both visuals in the form of photographs and audio in the form of popular music is more established particularly in relation to teaching introductory sociology. Such literature is closely aligned with the requirements of the research presented, which is concerned with developing an introductory approach for teaching the social aspects of sustainability within product design.

Literature suggests that the use of an audio-visual approach can have reflective benefits for students (Albers \& Bach, 2003; Hanson, 2002; Tan \& Pearce, 2011), and foster critical thinking and reflection by encouraging discussion in a group context by creating a shared experience (Albers \& Bach, 2003; Hanson, 2002; Hraba, Powers, Woodman \& Miller, 1980). This is important as this addresses the key perceived weakness of Net Generation learners: the ability to critically reflect (Holliday \& Li, 2004; Oblinger \& Oblinger, 2005b). Additionally, the careful use of photographs suits the visual preferences of the Net Generation, while the additional use of music is also noted in the literature as beneficial to learning (Ahlkvist, 2001; Albers \& Bach, 2003; Brkich, 2012).

Another benefit described in the literature is the use of audio-visual methods to address theory in the curriculum that involves difficult concepts (Hinds-Aldrich, 2012), which suits the complex nature of the social aspects of SPD.

\section{Methodology}

Workshops were conducted at 5 universities, 3 in England, 1 in Wales and 1 in Ireland, among undergraduate and postgraduate product design students. In total, 150 students took part in the workshops, which were conducted within modules that considered sustainable design.

Data collection consisted of a number of different formats to permit triangulation:

- Two student questionnaires were completed, one prior to students commencing the workshops and the other immediately after completion. The questionnaires were similar enabling the differences in individual students' understanding and attitudes to be measured.

- Audio recordings and photography were also used to record the students' interactions during the workshop sessions. The audio recordings were transcribed and analysed in conjunction with the images of the students mind maps and subsequent project work, using coding and clustering techniques.

- Students' reflective diaries that were maintained throughout the module were considered for references to the workshops and also analysed using coding and clustering techniques where applicable.

Coding and clustering was used to analyse these qualitative data sources because it permits the data obtained to be reviewed and dissected in a meaningful way while still keeping the relationships between the data intact (Miles \& Huberman, 1994).

Three separate workshops were offered each considering a different aspect of social SPD and themes derived from earlier research (Watkins, 2013):

- The first workshop 'Step into my World' featured photographs of individuals from diverse backgrounds and differing abilities and ages and encouraged the students to explore usercentred design issues under the 'design for the other $90 \%$ ' banner through the images and the use of a song that invited the listener to 'step into another's world'. The workshop was de- 
signed to introduce themes such as inclusive design, design for true need, co-design, social design, design for the aged and design for disability.

- The second workshop 'Localisation, Reuse and Emotionally Durable Design' considered the narrative and product lifecycle of products and the users' relationship to the products, addressing issues such as localisation, end of life considerations, emotionally durable design, personal meaning, personalisation, product reuse, secondary product life, cultural identity and employment. Photographs, brief text-based statements and atmospheric music were used to convey the message.

- The third workshop called 'Exploitation' was more holistic and controversial than the first two and encouraged students to consider the wider ethical issues surrounding design such as consumerism, global inequality, social equity, social justice, ethical consumption, globalisation and design activism. Photographs were intertwined with news clippings and underlined by a piece of popular music that questioned the effects of consumerism and globalisation.

Each workshop consisted of two elements, a 3-5 minute audio-visual introduction that was shown at the beginning, followed by a 45-minute group-based workshop that sought to encourage students to respond to what they had seen. Four prompt questions were also provided to aid group discussion during the 45-minute workshop element and students were actively encouraged to record their own thoughts and group discussions in the form of a mind map.

The design of the workshops was supported by the literature, which suggested that the visual methods should increase the relevance of the activity to the highly visual 'Net Generation' learners (Oblinger \& Oblinger, 2005b; Windham, 2005; Tapscott, 2009), while the use of carefully selected photographs could help foster indirect experiences with the content, enabling students to personalise aspects of sustainability (Murray, 2011). Furthermore, the opportunities for group work should appeal to the socially orientated nature of 'Net Gen' learners (Howe \& Strauss, 2003; Oblinger \& Oblinger, 2005b; Barnes, Marateo \& Ferris, 2007; Tapscott, 2009). The workshop should also encourage and provide opportunity for discussion, debate and critical reflection as well as engagement (Huckle \& Sterling, 1997; McNerney \& Davis, 1996). Finally, brainstorming as a reflective technique is recognised as important to the design thinking process (Seidel \& Fixson, 2013).

The audio-visual introductions were designed to be contemporary in style using photographs and popular music to capture the students' attention. This design deliberately mimicked 'You Tube' content style, where images or silent video are overlaid with a piece of popular music. Such a style is readily relevant and accessible to a 'Net Generation' audience, who are able to weave text, images and sound in a natural way (Oblinger \& Oblinger, 2005b).

The photographs used were selected intentionally to portray a number of different aspects, so that each audio-visual introduction could introduce a much larger range of social issues than a traditional lecture format could accommodate, if only at a superficial level. The music selected was carefully considered to ensure that the lyrics or the tone of the music were related to the issues being portrayed.

\section{Findings}

The following section will describe how the students related to the audio-visual format and the effectiveness of the workshops, and will consider an example of how the workshops impacted the students' work.

Students cited the audio-visual introductions as effective and informative, describing how the format helped them to think and noted the emotive nature of the music. One student in particular cited the format as a video and noted that it helped memorise aspects more readily as a result: 'Video in 2 nd activity \& learning from, interesting could let me memorise things more easily.' 
Students also discussed the effectiveness of the audio-visual introductions, responding positively to the style, citing the short length, simplicity, thought-provoking nature and ability to evoke discussion. The audio-visual introductions also provoked an emotional response among students who commented on how they found them 'powerful' and in the case of the final workshop 'Exploitation', the students found it 'shocking' and 'upsetting'.

\section{Audio}

The students commented positively on the inclusion of music, often commenting on the emotional nature of the music used and making links between the music and the visual content.

Students discussed the nature of the lyrics of the song used in the 'Step into my World' introduction. The song had the same title and described stepping into another person's world. The lyrics were effective in triggering discussion and led to a variety of user-centred empathic research approaches being suggested. Of note were empathic, co-design and ethnographic user-centred research and specifically relating such approaches to student group projects conducted at one of the universities. One student commented, 'Lyrics of the song take a step in my world, this suggests living in one of these peoples shoes for a day.'

\section{Visuals}

The use of images and the visual nature of the audio-visual introductions were noted among students throughout the questionnaires, workshop sessions and reflective diaries, with students describing the 'striking' nature of the photographs and composition: 'It was the wonderful selection of photos that made me stop and think.'

The visual nature was found to be particularly memorable to the students, with them commenting on specific images and later describing specific individuals and objects portrayed in the audio-visual introductions in their diaries and mind maps. Students also began to relate to the examples given in the audio-visual introduction personally, contextualising aspects such as emotionally durable design, personal meaning and reuse by citing objects that they have an affinity with.

When I saw the bit about the sentimental design so the guy with his first car it kind of reminded me of a project that I am working on at the moment restoring a 1962 Vespa which is almost finished now. It's kind of a piece of design that you relate to in a personal way $\left(1^{\text {st }}\right.$ year BSc student).

Similarly, the images in the 'Exploitation' audio-visual introduction appeared to be particularly memorable and were cited by several students, with comments describing the cramped working conditions in particular. While it was typically photographs from the audio-visual introductions that were cited, a number of students at each institution also recalled text-based quotes from the materials, such as 'One man's waste is another man's treasure' in the 'Localisation and Emotionally Durable Design' introduction.

\section{Effectiveness of the workshop style and format}

Students cited the workshops as enjoyable and valuable, describing how the workshops helped them broaden their thinking and outlook in respect to their design solutions.

Overall I thought the workshop was very beneficial as it opened my mind to looking beyond the obvious problem and look deeper into the situation to come up with a good solution $\left(2^{\text {nd }}\right.$ year BSc student).

Students also cited the group work and group discussion aspect of the workshops, recognising benefits of group work such as the consideration of different opinions and viewpoints. 
We then broke off into groups and discussed what we thought of the videos. We had to group with people we don't normally group with which was quite good because we saw different opinions ( $2^{\text {nd }}$ year BSc student).

Students reflected later in both their questionnaires and diaries on the conflicting views that arose from group discussion, especially in relation to the workshop 'Exploitation'. Students began to appreciate that there were often two equally valid points of view or arguments to a particular issue, grasping an important characteristic of the complexity of sustainability and demonstrating critical reflection.

The other question is well you can say China and India are going through their Industrial Revolution, which we went through. Our industrial revolution, where we had child labour, child chimney sweeps and you go through that, so it's almost like a rite of passage to go through, but how long has that lasted though, we had ours. We endorse it yeah, but it doesn't make it right does it. Yeah because when we had it other people weren't paying them, we were paying them $\left(2^{\text {nd }}\right.$ year BSc student $)$.

\section{Evidence of students applying learning from workshops}

There was evidence at 3 universities of students relating the workshop content to design projects that they were currently undertaking both within the modules that hosted the workshops and other modules.

An example of such a project outcome arising from the workshops is given below. This particular group of students continued to explore the theme of intergenerational design that they arrived at during the 'Step into my World' workshop. During the workshop session, the group noted that the 5 pictures of people were actually 5 different stories relating to their individual lives and sought to link them. In particular, the group described the loneliness of an elderly lady and how the youth were portrayed as a possible result of broken families (Figure $1)$.

Family the old lady doesn't have any and the guy with the hoody didn't look like he appreciated his family..... His angry because........yeah that's true broken family..... There's five different stories in that presentation I mean..... maybe you can link them together $\left(2^{\text {nd }}\right.$ year BSc student).

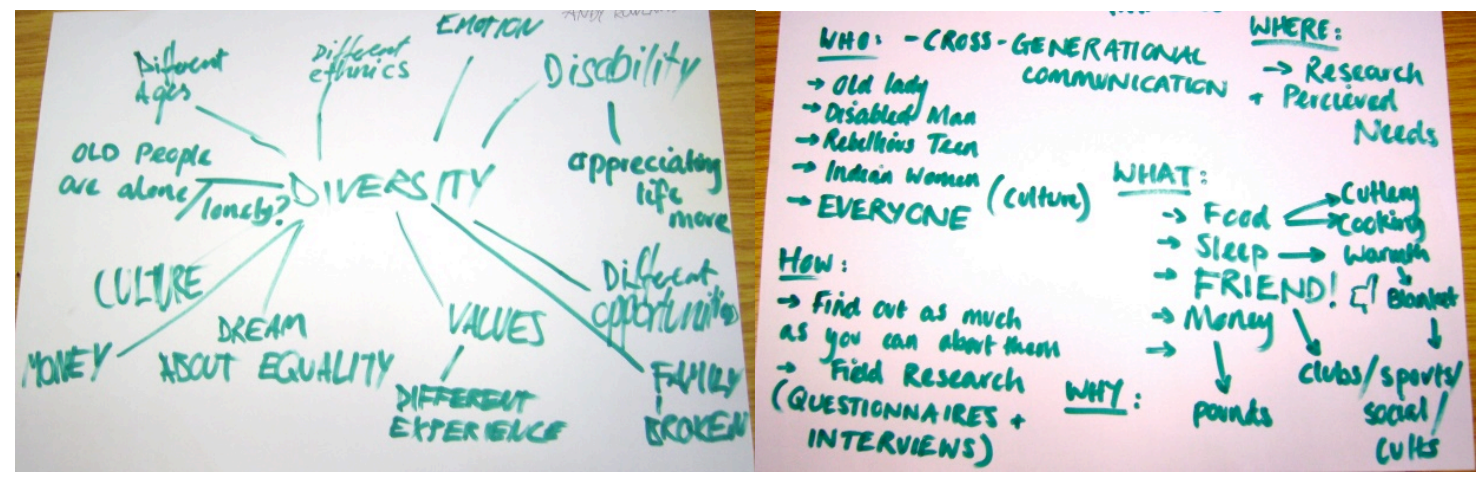

Figure 1. Mindmaps produced by the group in the 'Step into my World' workshop

The group then sought to produce a design that united different generations and produced a product design that served the needs of 3 generations, encouraging interaction and communi- 
cation between the generations in the form of multifunctional public seating that attempted to address the importance of family.

As part of this process, the students undertook user-centred design research interviewing 3 generations of families: grandparents, parents and grandchildren. From this, they designed public seating to be placed within a park environment (Figure 2). The seating is adaptable to suit a number of different uses and age groups, suiting the intergenerational criteria. Additionally, the seat was linked to the students' reflections in the 'Step into my World' workshop of the elderly lady being stuck indoors. In their project outcome, there were clear references to their learning and reflections as a result of their involvement in the 'Step into my World' workshop, developing aspects from their initial workshop reflections concerning broken families, social deprivation and loneliness in elderly people.

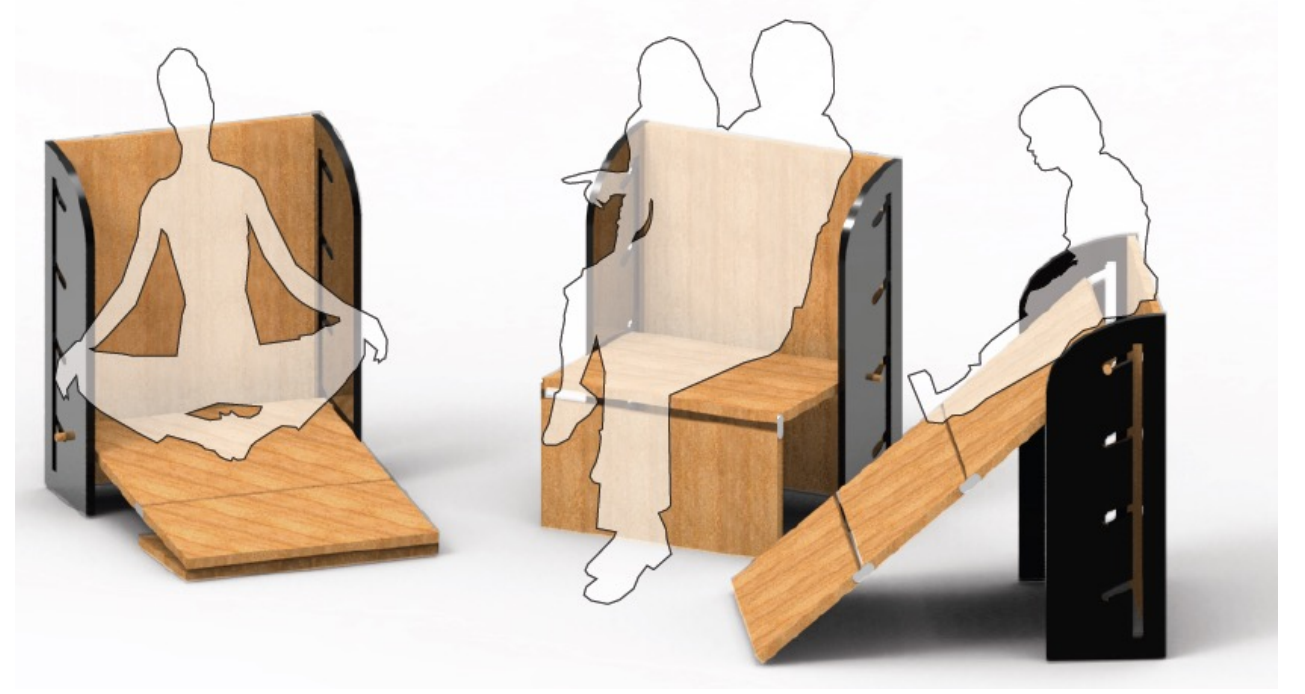

Figure 2. Design concept for intergenerational public seating

\section{Discussions}

\section{Audio nature}

Music was used in the audio-visual introductions for all three workshops, but the emotional nature of the music was only noted by students in response to two of the workshops, 'Step into my World' and 'Localisation and Emotionally Durable Design', recognising Crowther's (2012) view that music can evoke strong emotions.

All the students who commented on the inclusion of music were positive, suggesting that the music improved the presentation by providing additional meaning and understanding. Especially in the 'Step into my World' workshop, students elicited further meaning because of the addition of music.

The positive reaction and recognition that the music added to the learning experience in the 'Step into my World' workshop supports the literature findings (Ahlkvist, 2001; Albers \& Bach, 2003; Martinez, 1995). Furthermore, the lyrics of the song which invited the listener to 'step into another's world' were effective in formulating discussion and thinking (Ahlkvist, 2001; Albers \& Bach, 2003; Martinez, 1995) and led to the consideration of user-centred empathic research approaches including ethnography and co-design. The students considered how they could step into the world of the individuals portrayed in the audio-visual introduction by reflecting on the needs represented in the workshop when exposed to cultures outside of their own. 
Such observations were made by students at all of the universities where the 'Step into my World' workshop was conducted suggesting that the connection was made universally. This suggests that the literature findings relating to the personalisation of sustainability through the creation of an indirect experience using visual methods (Murray, 2011) could be extended further to include music as a key element among the 'Net Generation' learners.

\section{Visual nature}

The use of carefully selected photographs within the audio-visual introductions helped to foster the indirect experiences that Murray (2011) describes as important for the personalisation of sustainability. The responses from the students suggested that the photographs used were particularly evocative and memorable, expressing emotion and stories that students could link to the individuals portrayed.

The students described how the portraits of the people in the 'Step into my World' introduction gave an insight into their lives, and students typically made generalisations from each of the photographs to describe the lifestyle or needs of the individual portrayed, interpreting the image and deducing the meaning as described by Perkins (1994). This filling in of the gaps is also acknowledged by Murray (2011) in relation to the use of imagery, but cited as a disadvantage as it leads to generalisations. However, for the purposes of these workshops it was beneficial as the students began to derive needs and design solutions from their interpretations. Students also in part recognised that they were making generalisations and therefore recognised the need for user-centred research in relation to the message portrayed from the music.

The evocative nature of the photographs and the length of time for which each photograph was shown caused students to remember the image long after it was displayed. This was an intentional aspect of the design of the introductions, to allow time for the students to process the image. This importance of time to reflect has been noted in the literature (Hanson, 2002; Perkins, 1994). The length of time the photographs were shown for was particularly noticeable in the 'Step into my World' workshop, to the extent that it was almost disconcerting to the viewer. However, this could have influenced the particularly memorable nature of each individual portrayed, as all groups at each university readily discussed each individual portrayed within the 'Step into my World' workshop.

Individual photographs were instrumental in fostering discussion and, in some cases, critical debate as proposed in the literature (Hanson, 2002; Schell, Ferguson, Hamoline, Shea \& Thomas-Maclean, 2009), with multiple interpretations arising among the students. For example, students were divided in their opinions of the low-cost handmade artefacts featured in the 'Localisation and Emotionally Durable Design' audio-visual introduction. Some suggested that such reuse was letting companies off the hook when they should be ensuring recycling occurs at the end of life, while other students recognised the affordability and cultural relevance of reuse in developing countries.

Certain images led to in depth debate with students unravelling complex themes behind individual images, such as a simple 'Made in China' image. Students interpreted what this meant on multiple levels, reflecting on the effects of mass manufacture in the East, including labour issues, cost and the environmental effects of shipping. The discussion of labour issues during the 'Localisation and Emotionally Durable Design' workshop at one university was particularly interesting as the students involved at this institution had no prior exposure to the 'Exploitation' workshop materials but had effectively uncovered far wider reaching issues through the discussion of a single image.

This highlights the ability of students to draw multiple meanings through reflection on a single image. While the complete audio-visual introductions were intended to explore multiple aspects of social sustainability, it was interesting to note that this was also the case 
with specific single photographs within the audio-visual introductions. A simple 'Made in China' image elicited reflection as did an image of a pallet chair, through which students recognised all three pillars of sustainability, the economic, environmental and social aspects, amid group-based discussion and reflection.

Despite the social SPD focus of the 'Rethinking Design Series' workshops, some students explored and discussed aspects relating to the wider context of Product Design such as the aesthetic value of the reused examples or whether the reused examples were indeed examples of industrial design because they weren't mass produced. This suggested that the workshops had encouraged them to consider the content in terms of their wider practice, helping them integrate social sustainability rather than compartmentalise it. This finding addresses a key issue found in literature in SPD education (Ramirez, 2007a).

From the 'Exploitation' introduction, students noted a range of images with many focussing on those that shocked them the most relating to the Chinese factory workers and child labour. However, the greatest impact from this introduction appeared to be related to the supporting text included with the images, with students recalling the facts and figures quoted in relation to the hours worked and wages paid to the Chinese factory workers. This suggests that while the highly visual nature of the images was effective throughout the workshops, the students also memorised the key facts and figures particularly well, which could indicate that the students preferred the exact information that these portrayed in respect to the subjective nature of photographs.

However, the length of these almost headline-like text-based quotes also appeared to have been a key factor in the ability to be memorable as the students didn't cite other information given in longer text-based quotes in the 'Exploitation' and 'Localisation and Emotionally Durable Design' audio-visual introductions. Nevertheless, it should be highlighted that while the short text-based quotes were memorable, they didn't elicit the same level of reflection among the students as the photographs. Therefore, the text-based material was merely useful to convey understanding and give detail required for understanding the images.

\section{Conclusions}

The audio-visual nature of the workshop introductions proved to be effective both in engaging the students as well as being memorable. This was demonstrated by students reciting exact quotes and accurately describing detail in images. Moreover the audio (in particular 'Step into my World') led students to a deeper exploration of the content to explore empathic design research approaches.

More importantly, the audio-visual introductions were engaging enough to foster group discussion and debate among the students. It was this discussion and debate in the workshops that was found to have instigated critical reflection that was initially absent in the students' individual responses.

The findings suggest that the visual imagery used within the audio-visual introducetions was a highly effective way of portraying the content, and encouraged reflection among the learners, echoing the findings of both the audio-visual and 'Net Generation' literature. Furthermore, the use of audio added additional meaning for the students enhancing and adding to the literature on developing an indirect experience for personalising sustainability (Murray, 2011), which previously only considered visual resources through the use of photography.

The workshops also addressed a key issue described in the SPD education literature (Ramirez, 2007a) and academics in the earlier research interviews (Watkins, 2014a): the inability of students to apply their understanding of sustainability outside of a specialist module in their general practice. Instead, the workshops enabled students to draw links through discussion and reflection to other components of product design within the workshops and 
applied their learning from the 'Step into my World' workshop as shown earlier. Further work, however, could consider the wider impact of such audio-visual workshops across their studies rather than in individual modules.

The approaches used in these workshops enabled students to explore multiple aspects of social sustainability within a short span of time, promoting peer learning and learning through discovery, preferences of 'Net Generation' learners. The workshops were successful in addressing a range of social sustainability criteria and encouraged students to consider such issues in respect to their discipline.

It was intended from the outset of the research that the simple design and format of these workshops could be replicated by other academics in similar contextual and environmental settings. However, the researcher recognised that constructing the workshops requires an innate ability to recognise appropriate images and music, skills that the researcher possessed as a photographer with a large personal music selection, but may prove limiting to others; therefore, guidance on sources of resources would be required.

\section{Matthew Watkins}

PhD, Senior Lecturer in Product Design and Course Leader BSc Product Design

Nottingham Trent University, School of Architecture, Design and the Built Environment,

Nottingham, England

Email address: matthew.watkins@ntu.ac.uk 


\section{References}

Ahlkvist, J. A. (2001). Sound and Vision: Using Progressive Rock to Teach Social Theory. Teaching Sociology, 29(4), 471-482. doi: 10.2307/1318948

Albers, B. D. \& Bach, R. (2003). Rockin' Soc: Using Popular Music to Introduce Sociological Concepts. Teaching Sociology, 31(2), American Socio. doi: 10.2307/3211313

Barnes, K., Marateo, R. \& Ferris, S. (2007). Teaching and Learning with the Net Generation. Innovate, 3(4). Retrieved from http://innovateonline.info/pdf/vol3_issue4/Teaching_and_Learning_with_the_Net_Generation.pdf

Brkich, C. A. (2012). Music as a weapon: Using popular culture to combat social injustice. The Georgia Social Studies Journal, 2(1), 1-9

Crowther, G. (2012). Using Science Songs to Enhance Learning: An Interdisciplinary Approach. CBE-Life Sciences Education , 11(1 ), 26-30. doi: 10.1187/cbe.11-08-0068

Elkington, J. (1998). Cannibals with forks: the triple bottom line of 21st century business. Gabriola Island, BC: New Society Publishers

Griffith J., S. \& Bamford, R. (2007). Embedding the principles of responsible design into student practice from 1st year. In Connected 2007 International Conference on Design Education. University of New South Wales, Sydney, Australia. Retrieved from http://www.connected2007.com.au/finalpapers/start.swf

Griffiths, R. \& O’Rafferty, S. (2010). Sustainable social design. In F. Ceschin, C. Vezzoli, \& J. Zhang (Eds.), Sustainability in Design: NOW! (pp. pp.944-951). Bangalore, India: LeNs. Retrieved from www.lens.polimi.it

Hanson, C. M. (2002). A Stop Sign at the Intersection of History and Biography: Illustrating Mills's Imagination with Depression-Era Photographs. Teaching Sociology, 30(2), 235-242 American Socio. doi: $10.2307 / 3211385$

Hinds-Aldrich, M. (2012). Teaching theory analogically: Using music to explain criminological theory. Journal of Criminal Justice Education, 23(4), 481-499. doi: 10.1080/10511253.2012.665934

Holliday, W. \& Li, Q. (2004). Understanding the millenials: Updating our knowledge about students. Reference Services Review, 32(4), 356-366. doi: 10.1108/00907320410569707

Howe, N. \& Strauss, W. (2003). Millenials go to college: Strategies for a new generation on campus: Recruiting and admissions, campus life, and the classroom (2nd ed., p. 100). American Association of Collegiate Registrars and Admissions Officers

Hraba, J., Powers, E., Woodman, W. \& Miller, M. (1980). Social change through photographs and music: A qualitative method for teaching. Qualitative Sociology, 3(2), 123-135. doi: 10.1007/BF00987267

Huckle, J. \& Sterling, S. (1997). Education for sustainability (p. 233). London: Earthscan.

Martinez, T. A. (1995). Where popular culture meets deviant behavior: Classroom experiences with music. Teaching Sociology, 23(4), 413-418 American Socio. doi: 10.2307/1319171

McNeely, B. (2005). Educating the Net Generation - Using technology as a learning tool, not just the cool new thing. EDUCAUSE. Retrieved from http://www.educause.edu/educatingthenetgen

McNerney, C. \& Davis, N. D. (1996). Education for Sustainability: An Agenda for Action. Pennsylvania: Diane Publishing Company

Miles, M. B. \& Huberman, A. M. (1994). Qualitative Data Analysis: An expanded sourcebook. (2nd ed.). Thousand Oaks, CA: Sage

Murray, P. (2011). The Sustainable Self: A Personal Approach to Sustainability Education (p. 240). Earthscan

Oblinger, D. \& Oblinger, J. (2005a). Educating the Net Generation. EDUCAUSE. Retrieved from http://www.educause.edu/educatingthenetgen

Oblinger, D. \& Oblinger, J. (2005b). Educating the Net Generation - Is it age or IT: First steps toward understanding the net generation. EDUCAUSE. Retrieved from http://www.educause.edu/educatingthenetgen 
Palfrey, J. \& Gasser, U. (2008). Born digital: Understanding the first generation of digital natives. New York: Basic Books

Perdan, S., Azapagic, A. \& Clift, R. (2000). Teaching sustainable development to engineering students. International Journal of Sustainability in Higher Education, 1(3), 267 - 279. doi: 10.1108/14676370010378176

Perkins, D. N. (1994). The Intelligent Eye: Learning to Think by Looking at Art (p. 95). Los Angeles: Getty Publications

Prensky, M. (2001). Digital natives digital immigrants. On the Horizon, 9(5). Retrieved from http://www.nnstoy.org/download/technology/Digital Natives - Digital Immigrants.pdf. doi: $10.1108 / 10748120110424816$

Ramirez, M. (2007a). Promoting sustainability through industrial design studio projects. In Connected 2007 International Conference on Design Education (pp. 1-5). University of New South Wales, Sydney, Australia. Retrieved from http://www.fbe.unsw.edu.au/staff/mariano.ramirez/CONNECTED2007promotingsustainability $3 \mathrm{r} . \mathrm{pdf}$

Ramirez, M. (2007b). Sustainability integration in industrial design education: A worldwide survey. In Connected 2007 International Conference on Design Education. University of New South Wales, Sydney, Australia. Retrieved from http://www.fbe.unsw.edu.au/staff/mariano.ramirez/CONNECTED2007-idschoolsworldwide2r.pdf

Schell, K., Ferguson, A., Hamoline, R., Shea, J. \& Thomas-Maclean, R. (2009). Photovoice as a teaching tool: Learning by doing with visual methods. International Journal of Teaching and Learning in Higher Education, 21(3), 340-352

Seidel, V. P. \& Fixson, S. K. (2013). Adopting “design thinking” in novice mulitdisciplinary teams: the application and linits of design methods and reflexive practices. Journal of Product Innovation Management, 30(S1), 19-33. doi: 10.1111/jpim.12061

Tan, E. \& Pearce, N. (2011). Open education videos in the classroom: Expolring the opportunities and barriers to the use of YouTube in teaching introductory sociology. Research in Learning Technology, 19(1)

Tapscott, D. (1998). Growing up digital: The rise of the net generation (1st ed., p. 338). New York: McGraw Hill

Tapscott, D. (2009). Grown up digital: How the net generation is changing your world (1st ed., p. 384). New York: McGraw-Hill

Vezzoli, C. (2006). Design for sustainability: The new research frontiers. In 7th Brazilian Conference on Design. Curitiba. Retrieved from http://www.design.ufpr.br/ped2006/apresentacoes/vezzoli.pdf

Watkins, M. A. (2013). Defining the social dimension of Sustainability in Product Design. Key Engineering Materials, 572, 24 - 27. doi:10.4028/www.scientific.net/KEM.572.24. doi: 10.4028/www.scientific.net/KEM.572.24

Watkins, M. A. (2014a). An investigation into effective methods for teaching social sustainability within product design in British and Irish Universities. Loughborough University. Retrieved from https://dspace.lboro.ac.uk/2134/14155

Watkins, M. A. (2014b). Towards an Understanding of the Social Aspects of Sustainability in Product Design: Teaching HE students in the UK and Ireland through reflection and peer learning. Design and Technology Education: An International Journal, 19(1), 40-47

Windham, C. (2005). Educating the Net Generation - The student's perspective. EDUCAUSE. Retrieved from http://www.educause.edu/educatingthenetgen 